\title{
LGBTQ Persons' Pregnancy Loss Disclosures to Known Ties on Social Media
}

\author{
Disclosure Decisions and Ideal Disclosure Environments
}

\author{
Cassidy Pyle \\ University of Michigan School of Information \\ Ashley Lacombe-Duncan \\ University of Michigan School of Social Work
}

\begin{abstract}
Pregnancy loss is a common yet stigmatized experience. We investigate (non)disclosure of pregnancy loss among LGBTQ people to known ties on identified social media as well as what constitutes ideal socio-technical disclosure environments. LGBTQ persons experiencing loss face intersectional stigma for holding a marginalized sexual and/or gender identity and experiencing pregnancy loss. We interviewed 17 LGBTQ people in the U.S. who used social media and had recently experienced pregnancy loss. We demonstrate how the Disclosure Decision-Making (DDM) framework explains LGBTQ pregnancy loss (non)disclosure decisions, thereby asserting the framework's ability to explain (non)disclosure decisions for those facing intersectional stigma. We illustrate how one's LGBTQ identity shapes (non)disclosure decisions of loss. We argue that social media platforms can better facilitate disclosures about silenced topics by enabling selective disclosure, enabling proxy content moderation, providing education about silenced experiences, and prioritizing such disclosures in news feeds. CAUTION: This paper includes quotes about pregnancy loss.
\end{abstract}

\section{CCS CONCEPTS}

- Human-centered computing; • Human-computer interaction (HCI); • Empirical studies in HCI;

\section{KEYWORDS}

pregnancy loss, miscarriage, LGBTQ health, reproductive health, social media, disclosure, intersectional stigma, intersectionality

\section{ACM Reference Format:}

Cassidy Pyle, Lee Roosevelt, Ashley Lacombe-Duncan, and Nazanin Andalibi. 2021. LGBTQ Persons' Pregnancy Loss Disclosures to Known Ties on Social Media: Disclosure Decisions and Ideal Disclosure Environments. In CHI Conference on Human Factors in Computing Systems (CHI '21), May 08-13, 2021, Yokohama, Japan. ACM, New York, NY, USA, 17 pages. https://doi.org/10.1145/3411764.3445331

Permission to make digital or hard copies of all or part of this work for personal or classroom use is granted without fee provided that copies are not made or distributed for profit or commercial advantage and that copies bear this notice and the full citation on the first page. Copyrights for components of this work owned by others than the author(s) must be honored. Abstracting with credit is permitted. To copy otherwise, or republish, to post on servers or to redistribute to lists, requires prior specific permission and/or a fee. Request permissions from permissions@acm.org.

CHI '21, May 08-13, 2021, Yokohama, Japan

(C) 2021 Copyright held by the owner/author(s). Publication rights licensed to ACM. ACM ISBN 978-1-4503-8096-6/21/05 ..\$15.00

https://doi.org/10.1145/3411764.3445331

\author{
Lee Roosevelt \\ University of Michigan School of Nursing \\ Nazanin Andalibi \\ University of Michigan School of Information
}

\section{INTRODUCTION}

Social media platforms enable users to share a range of content, from everyday thoughts and feelings to significant life events and milestones. For example, Facebook facilitates the sharing of milestones through the life event feature, which allows users to select and share a life event from a pre-existing list of categories having to do with work, education, family, or health and wellness, to name a few. Users can also customize a life event to fit their unique disclosure needs. Disclosure is defined by Jourard as an "accurate portrayal of the self to others" [56], and is one means by which people can seek support in the aftermath of a difficult life experience. Disclosures can also lead to support, meaningful connections, or reduced stigma surrounding sensitive topics [6]. Although "positive" life event disclosures are rather common, it can be difficult to disclose a stigmatized life event [4, 7, 48, 49].

Pregnancy loss, here referring to an undesired loss of a pregnancy at any gestational stage, represents a stigmatized experience in that it does not abide by the societal expectation of "joyful maternity" [84]. Instead, it represents a break in the expected linear and normative passage to motherhood. For some, it is seen as a personal failure to live up to expectations of motherhood [65], which are created and reproduced in the context of the larger patriarchal society that associates (cis) women's value with their ability to produce biological children [43] and devalues trans and nonbinary people who can and do produce biological children. This "personal failure" is then judged intra- as well as inter-personally, fostering a societal silence about a uniquely common experience [10]. As a result, the experience of pregnancy loss is often experienced as a stigmatized event [70] that even feminist discourse and scholarship has neglected to some extent [62].

LGBTQ (lesbian, gay, bisexual, transgender, queer/questioning) people can and do desire and experience pregnancy [36, 99, 100], and some of these pregnancies end in loss. At best, if at all, LGBTQ pregnancy loss exists at the margins of reproductive health societal narratives [96]. LGBTQ people who experience pregnancy loss manage intersectional stigma (describing an intersectional [34] approach to stigma) [95] as a result of possessing at least two often stigmatized identities. Not only are LGBTQ people embedded in a pervasive heteronormative and cisnormative culture that directs stigma toward sexual and gender minorities who are labelled and subsequently devalued [75], but they also experience stigma in relation to their pregnancy loss.

In the aftermath of their loss, many individuals experience mental health challenges $[58,63,76,77]$. Social support, or resources 
exchanged among interpersonal ties [27] can be beneficial to the healing process after a loss [103]. Traditionally, face-to-face support groups have attempted to connect those who experience pregnancy loss with other individuals, groups, and communities [61, 62]. More recently, online spaces have served similar purposes [29, 62]. However, both offline and online social support interventions have failed to consider LGBTQ people who experience pregnancy loss [29, 61, 62]. To date, research concerning pregnancy loss and technology has largely centered cisgender heterosexual women (e.g., [4]).

Social media platforms provide opportunities for disclosures and support exchange. For example, there are online spaces which typically provide some separation from one's network of known ties and may afford some degree of anonymity. Identified (i.e., known, non-anonymous) social media users may also benefit from disclosing experiences such as loss to identified ties with whom they have pre-existing relationships (e.g., family, friends). Prior social media research has examined disclosure behaviors and decisions in stigmatized contexts including mental health, chronic health conditions, gender transition, sexual assault, and pregnancy loss (for cisgender heterosexual women) [4, 6-9, 47, 49, 97].

Disclosure decisions of pregnancy loss by cisgender, heterosexual women on identified social media have been explained by the Disclosure Decision-Making (DDM) framework [2, 4, 8]. This framework considers six factors that contribute to (non)disclosure decisions (self-related, audience-related, network-level, societal, temporal, and platform and affordance-related). Researchers have also examined disclosures of LGBTQ identities on social media [15, 49, 53], highlighting related disclosure decisions' complexities. We lack in-depth knowledge about online disclosure experiences at the intersection of loss and LGBTQ identity, which we expect to be complicated due to intersectional stigma (due to LGBTQ identity and pregnancy loss). Guided by previous work, an intersectional approach [28, 34], and the concept of intersectional stigma [95], this study focuses on LGBTQ experiences with pregnancy loss to complicate existing knowledge on disclosure decisions on identified social media.

In this study, we conducted interviews with 17 LGBTQ people who experienced pregnancy loss and who used social media in order to investigate how intersectional stigma and one's LGBTQ identity influences decisions to disclose (or not disclose) experiences with pregnancy loss on social media and what ideal disclosure spaces entail. Although we did not set out to focus on one social media platform, Facebook was identified as the platform most important to participants in reflecting on their loss disclosure decisions and experiences. As an identified social network site wherein one's identity and connections are known, this context encompasses unique challenges to disclosure that are less present in anonymous spaces (e.g. impression management and context collapse concerns [69]).

We make several contributions to human-computer interaction and social computing research on online stigmatized disclosures. First, we assert the utility of the Disclosure Decision-Making (DDM) framework [4] in explaining social media (non)disclosure decisions specifically for LGBTQ people who have experienced pregnancy loss and thus manage intersectional stigma. Second, we uncover how one's LGBTQ identity influences factors that drive (non)disclosure decisions according to the DDM framework. Third, we highlight characteristics of ideal online loss disclosure environments reported by LGBTQ people experiencing pregnancy loss. Finally, we argue that social media designers can develop platforms that facilitate disclosures of stigmatized life events through enabling and encouraging selective disclosures to pre-existing ties, incorporating features that educate and advise audiences about stigmatized life experiences, and prioritizing stigmatized disclosures in addition to content laden with positive emotions.

\section{RELATED WORK}

\subsection{LGBTQ Pregnancy and Parenting}

A significant number of LGBTQ people wish to become pregnant $[36,99,100]$. LGBTQ people's journey to parenthood can be more complex or involve concerns that do not necessarily apply to their cisgender, heterosexual peers. Although the topic of LGBTQ parenthood has increased in visibility due to coverage in press and television shows, there remains a dearth of relatable role models who can guide consciousness of and conversations around parenthood for the LGBTQ community, particularly for transgender and nonbinary people [86]. When LGBTQ people do decide to become parents, they face particular conception and pregnancy challenges, including logistical [83], financial [33], and emotional [40] challenges. Logistical challenges include choosing a pathway to parenthood, such as surrogacy or co-parenting [85]. For people or couples who do not produce their own sperm, another challenge is the negotiation and renegotiation of access to, as well as the transportation and storage of, sperm [82]. Financially, paying for expensive fertility treatments such as In vitro fertilization (IVF) can be challenging for LGBTQ aspiring parents [33]. Emotionally, many LGBTQ people report a pervading sense of isolation and stress at every point in the pregnancy journey, from conception to parenthood, in large part due to hetero-normativity and cis-normativity [24, 40]. Hetero-normativity and cis-normativity refer to ideologies that posit heterosexual and cisgender people as a norm and a standard to strive toward $[67,75]$. These ideologies can be pervasive among health care providers who may not understand LGBTQ pathways to parenthood and may make hetero-normative or cis-normative assumptions [20, 24, 52, 60, 64]. Furthermore, these ideologies are damaging because they devalue and render LGBTQ people's identities and experiences invisible [67]. Some LGBTQ people who attempt to become pregnant also face overtly discriminatory comments and treatment from medical professionals including improper pronoun use/misgendering and outright exclusion from medical practices and treatments $[24,64,100,101,103]$. These feelings of isolation and exclusion from hetero-normativity and cis-normativity do not just happen in health care settings. They also occur in LGBTQ peoples' daily lives. For instance, pregnant transgender men have reported feeling isolated and excluded as a result of lack of representation and the danger of being "out" [24]. Lesbian non-biological mothers also report losing relationships with extended family and with those in the lesbian community over their decision to reproduce, and fear ostracism from heterosexual mothers $[59,102]$. Taken together, LGBTQ people desiring pregnancy face myriad challenges, some of which are uniquely shaped by their LGBTQ identities.

\subsection{LGBTQ Pregnancy Loss}

Approximately $20 \%$ of pregnancies in the United States will result in pregnancy loss, an experience that is both common and 
incredibly challenging [91]. To date, we have not found statistics specifically for LGBTQ experiences with pregnancy loss. Pregnancy loss is stigmatized within the patriarchal system of power, largely because women's value is conflated with their ability to produce biological children [43]. People who experience pregnancy loss face intrapersonal and interpersonal stigma, as they internalize stigma and experience judgment from others [41, 62]. Specifically, they may blame themselves for their loss or may receive stigmatizing reactions from others [41, 62]. After a pregnancy loss, people can experience myriad challenges, including increased depressive and anxiety symptoms and intense emotions, such as shock, devastation, self-blame, and anger [58, 63, 76, 77]. Paradoxically, a lack of social support has been associated with a higher risk of depressive symptoms in the wake of pregnancy loss, yet the stigmatized nature of the event makes reaching out for support challenging. [103].

While most people who experience pregnancy loss share experiences of grief, this grief may be amplified and compounded for LGBTQ people, largely because of the increased effort involved with planning and achieving pregnancy [14, 33, 55, 82, 101]. For LGBTQ people, this experience of stigma surrounding pregnancy loss is combined with discrimination, which only makes pregnancy loss an even more "silent burden" for this population [32, 55, 83]. Prior studies demonstrate how homophobia, transphobia, heterosexism, and cissexism infiltrate the loss experience. They describe partners who are forced to wait outside while someone receives the news of the loss and who are not included in memorial activities such as burial arrangement [32, 82]. This discrimination can result in LGBTQ people being less inclined to access support resources, such as local, in-person loss support groups that could benefit them in the time following the loss [32].

In in-person settings, LGBTQ people often experience fear of how others will respond to their loss, compromising their ability to receive social support [33]. Research suggests how unhelpful responses, such as being urged to simply "try again", are rooted in heteronormativity and a lack of understanding of the multiple barriers to pregnancy for LGBTQ people [83]. Even heterosexual people experience insensitive or hurtful comments following a pregnancy loss, and for LGBTQ people these hurtful comments may be exacerbated and may directly relate to their LGBTQ identity $[29,76]$.

\subsection{Social Media and LGBTQ Individuals}

Many LGBTQ people derive benefits from social media use. For example, social media can provide a place for LGBTQ people to explore, experiment with, and obtain support for their identity $[31,53,74]$. Facebook and Tumblr are examples of platforms that LGBTQ people use to explore identities and exchange social support $[23,26,47,51]$. Social support, including support exchanged via social media, is associated with positive mental health outcomes for LGBTQ people [72].

The ability to seek social support in online spaces is often predicated on disclosure of personal or sensitive information, typically information related to one's identity $[49,53]$. There is complexity added to identity disclosures when the identity is stigmatized [73] While disclosure can be beneficial [1], it can equally be a stressful experience due to concerns about how others will react and/or respond [49]. Furthermore, disclosures made on social media can be stressful since individuals have limited control over them [15]. LGBTQ users engage in a variety of strategies to control disclosures and manage privacy. For example, people undergoing gender transition report strategies such as using "lists" to disclose to subsets of one's network, unfriending, switching to a new profile, and maintaining multiple profiles [49]. These strategies are afforded by site features but are problematic because they are associated with stress [49]. Furthermore, the ongoing self-presentation work performed by LGBTQ users on Facebook has even been described as "personally treacherous" [92].

In addition to these challenges, dominant commercial social media platforms possess features that may prevent LGBTQ people from reaping benefits. Prior work has investigated some of the challenges LGBTQ users face with regard to self-presentation and identity disclosure or concealment as a result of social media platforms' policies (i.e. "real-name" policies, HIV disclosure policies, binary gender "encoding strategies") [13, 22, 26, 97], orientations toward privacy $[22,26]$, and lack of features dedicated to the management of digital artifacts [50] in addition to the phenomenon of context collapse (i.e., flattening of one's audience groups into one overarching group) [38].

In summary, past work has examined the online social supportseeking practices of LGBTQ people and have acknowledged difficulties around online disclosure for this population as well as site features that may compromise the ability for LGBTQ people to meet their social support and disclosure needs. While past research provides key insights about LGBTQ identity disclosure on social media, our focus here is how LGBTQ people disclose (or not) other sensitive experiences on social media, such as experiences related to reproductive health complications (e.g., pregnancy loss).

\subsection{Social Media and the Pregnancy Loss Experience}

When people experience pregnancy loss, they often create and disclose narratives that expand society's understanding of this traumatic process and acknowledge that what they have experienced is real $[55,70]$. The internet broadly (e.g., support forums), and social media platforms specifically (e.g., Facebook support groups), constitute digital spaces wherein these narratives can be published and distributed. These online support services provide people with the opportunity to make sense of, and express their emotions to, an audience of supportive others [29]. Unfortunately, many LGBTQ people's experiences of loss fail to fit into the narratives of pregnancy loss circulated on web-based support boards predominantly by heterosexual and cisgender women [84]. This compromises LGBTQ people's ability to elicit social support in this way, since heterosexist beliefs may cause them to be left out of the narrative of who has the "right" to be a gestational parent and whose loss "counts" [29]. Because LGBTQ people face unique pregnancy and loss-related challenges, along with challenges related to receiving support online, it is imperative that their experiences of pregnancy loss and how they share these experiences online receive scholarly attention.

Prior work has primarily examined how cisgender heterosexual women choose to share about experiences with pregnancy loss on identified social media (e.g., Facebook where one is typically 
connected to others they know and uses physical world names) [4], what strategies they take [4, 8], and what outcomes they perceive [1]. Through this work, Andalibi and Forte provide a Disclosure Decision-Making Framework (DDM) that explains factors informing (non)disclosures and indirect disclosures of stigmatized experiences on social media $[2,4,8]$. These include factors related to the self, audience, network, society, temporality, and platform affordances. Further, Andalibi reviewed extant disclosure literature on social media in stigmatized contexts and argued that the DDM framework provides a unifying lens to examine disclosure decisions of stigmatized experiences on social media across contexts [2]. Subsequent work has demonstrated the utility of the DDM in sexual abuse disclosures [11, 44]. However, empirical investigation is needed to understand the extent to which the DDM framework explains (non)disclosure decisions specifically for populations experiencing intersectional stigma and how it might be refined. We observed how participants' disclosure decisions identified through our inductive open coding, mapped or did not map to factors identified by the DDM.

In summary, this past work provides important insights about pregnancy loss disclosure processes in social media platforms, but not for LGBTQ individuals or other intersecting stigmatized experiences and identities more broadly, raising questions about how LGBTQ people use individual social media profiles where they are connected to networks of known ties to share experiences with pregnancy loss.

\subsection{Intersectionality as a Guiding Theoretical Framework}

Intersectionality has been found to be an influential theoretical framework in many academic disciplines as well as a practical tool to further social movements [28]. Intersectionality, rooted in Black feminism, activism, and Critical Race Theory, has a long history dating back to social movements of the 1960s [28]. Crenshaw [34] coined the term intersectionality building on this history and gave legitimacy to examinations of intersectional phenomena in the academy [28]. Intersectionality powerfully describes how interlocking systems of oppression complicate our understandings of one's experiences [28]. In addition to providing a framework for understanding experiences of oppression, intersectional approaches also consider social support, which emerges "when people with similar identities unite" [95]. This paper, as described below, employs an intersectional approach to understand how disclosures of a stigmatized life experience on identified social media can reveal both the interlocking oppressions faced by LGBTQ people experiencing pregnancy loss and the ways in which they can unite around common experiences to exchange social support.

The concept of intersectional stigma reflects an intersectional approach to stigma. Stigma, or a social process that involves labeling, stereotyping, and discriminating against a person or group to exert social control, can be perpetuated at structural, interpersonal, and intrapersonal levels [66]. Structurally, stigma can be reproduced when discriminatory or otherwise exclusionary policies become institutionalized [66, 93]. Interpersonal interactions can reproduce enacted stigma when people engage in discriminatory actions toward the stigmatized person or group [93]. Intrapersonally, individuals can internalize stigma and therefore experience felt normative stigma, meaning that they adopt negative attitudes toward themselves or their social group or hold a perception that others harbor negative attitudes toward them [93, 98]. Intersectional stigma describes the matrix of oppressions individuals face as a result of their overlapping stigmatized identities [95]. While communicating about stigma can be beneficial, not all are equal in leveraging the power of disclosure to achieve such benefits. For example, when individuals experiencing stigma (e.g., depression, sexual assault) are also members of a stigmatized or otherwise marginalized social group (e.g., LGBTQ, immigrant, Black), they may face unique barriers to disclosures that are related to their intersecting stigmatized experiences and identities (compared to individuals who are not members of marginalized social groups). LGBTQ people's experiences with pregnancy loss illustrate one configuration of intersectional stigma - a lens that guides this present study.

In this paper, we use an intersectional intracategorical approach - whereby we focus on a particular social group at a neglected point of intersection (i.e., people who have experienced pregnancy loss, with LGBTQ identity as a neglected point of intersection) [71] - in order to examine LGBTQ individuals' disclosure decisions in relation to pregnancy loss on social media. We also explore how our findings relate to the DDM framework developed in prior work in which intersectional stigma was not considered. We ask the following research questions: (1) What factors shape LGBTQ individuals' decisions to (not) disclose experiences of pregnancy loss on identified social media to networks of known ties? (2) What constitutes an ideal socio-technical disclosure spaces for LGBTQ individuals enduring pregnancy loss?

\section{METHODS}

Positionality. The research team consisted of members of the LGBTQ community, including LGBTQ people who have experienced pregnancy loss and people of color. One team member, a human-computer interaction researcher, is an expert in online identity, emotions, and marginality, while another, a nurse midwife, is an expert in LGBTQ-affirming care. Another team member is a social worker with expertise in intersectional stigma and healthcare access for LGBTQ people who hold other marginalized identities or who have experienced marginalizing events.

Recruitment. We conducted semi-structured interviews in April 2019 with individual participants who met the following criteria: a) self-identified as lesbian, gay, bisexual, transgender, queer (LGBTQ) or another sexual/gender minority; b) had experienced pregnancy loss or had been in an intimate partnership in which a pregnancy was lost in the last two years; c) used any social media; d) lived in the United States at the time of the study; and e) were over the age of 18 .

The Principal Investigators recruited participants through their personal networks, either by word-of-mouth or through their social media networks on Facebook and Twitter. To allow us to select a diverse array of participants of various sexual orientations, gender identities, races/ethnicities, socio-economic statuses, and with varied social media use habits, interested participants were first asked to complete a brief 5-minute screening survey. The majority $(86.4 \% ; 38$ out of 44$)$ of those screened met the inclusion criteria. 
Of those, 35 were contacted to participate in an interview and 17 participated. We stopped recruiting participants once we began to hear similar stories. Table 1 provides aggregated sociodemographic data about the 17 interviewed participants.

Methods. We chose to conduct semi-structured interviews in order to enable participants to feel control over the flow of the interview and comfort with sharing their experiences with the interviewers. Interviews were conducted entirely virtually, utilizing the participants' communication tool of choice (e.g., Skype, phone). Participants chose to keep their video off or on. In order to be sensitive of the needs of bereaved interviewees, we followed best practice guidelines designed to manage participant distress that were specifically adapted to virtual interviews [57]. At particularly emotionally charged points during the interviews, we asked participants if they would like to pause or end the interview, but no one did. Interviews lasted between 27 and 97 minutes (mean $=68$ minutes). Interviewers utilized one of two interview guides: one for participants who had physically experienced pregnancy loss and one for participants who were partnered with someone who physically experienced pregnancy loss. These interview guides covered topics such as general life changes during pregnancy, gaps and needs after experiencing pregnancy loss, online and offline disclosure of pregnancy loss, and social support desires. Follow-up questions asked about specifics about their social media use as well as reasons for use or non-use. All interviews were audio-recorded and transcribed verbatim. Each participant completed an online informed consent form before the interview. After the interview, participants were provided with honorarium in the form of a $\$ 25$ gift card. Our institution's Institutional Review Board classified the study as exempt and approved all study procedures.

We opted to include in our study partners of those who directly experienced pregnancy loss because individuals who are in relation to those who experience direct stigma may experience secondary stigma [80] or stigma by association [45]. Additionally, because many LGBTQ couples had to make the complex decision about which person should carry the pregnancy, there is an added component to the pregnancy and loss experience for LGBTQ people who directly experience loss and their partners that is different from cisgender, heterosexual people.

Analysis. We used memos and discussed interviews during data collection to aid in identifying patterns before beginning formal analysis to inform data collection, later confirmed by formal analysis. We followed thematic analysis [94] procedures to inductively create codes and themes. Four researchers independently opencoded three transcripts and met to develop an initial set of codes. Next, one researcher coded the remainder of the data and engaged in weekly discussions about the coding process with another researcher. Through this process, they refined codes and conceptualized themes. Finally, all researchers reviewed the codes and themes and further conceptualized broader themes. The first author then used relevant codes and themes that address our research question in this paper. While we present our findings organized through the DDM framework, we did not set out to do so. Our analysis was open and flexible looking for reasons for (non)disclosure. It was through the iterative process of creating themes that we looked for similarities and differences with the DDM. As we will see, all (non)disclosure motivations and factors were covered within the existing framework, and so we did not create new themes.

Limitations. Our sample overrepresented white, cisgender, partnered, educated, employed, and urban women, over half of whom earned more than $\$ 75,000$ per year. This overrepresentation in our sample reflects the ways in which classism and white supremacy intersect to privilege white people with a higher socio-economic status. Specifically, the intersection of classism and white supremacy shape who is likely to access reproductive support and health care (white people of higher socio-economic status) [16, 37] and, thus, who experiences biological pregnancy and is likely to participate in this study. Thus, while our participants largely were disadvantaged by cissexism, heterosexism, and patriarchy, they were also privileged by race and class, which may have decreased the risks associated with disclosure. In the future, we seek to work with community partners who work with transgender and nonbinary people as well as people of color to elicit their (non)disclosure experiences on social media in more depth and breadth. Intersectionality remains a relevant framework for our study despite our sample limitations because it is an analytic tool to understand intersecting systems of power which produce both privilege and oppression. Although our sample was limited, it allowed us to gather data from people who identified with a wider range of sexual orientations than most LGBTQ reproductive health literature, which almost exclusively focuses on lesbian women [90]. Furthermore, 16 participants were "out" to their Facebook networks about their LGBTQ status; it is possible that future work with individuals who had not disclosed their LGBTQ status to known ties on Facebook would identify additional challenges. Temporal factors (one factor in the DDM) did not surface as a theme in our data; this might have been different if our sample included people who were outside the 2 year criteria or with more participants who had experienced multiple losses. Future work should investigate these factors in greater detail with populations experiencing intersectional stigma. Despite sampling limitations, we learned a substantial amount from our participants about LGBTQ pregnancy loss and disclosure in online spaces that connect people to known ties. We did not set out to focus on these online spaces in particular, as we did not know what online spaces would be important to participants in one way or another. However, in the process of collecting and analyzing our data, we learned that Facebook, a platform that connects users to known ties, played a unique and central role in coping for participants in relation to pregnancy loss and navigating the pregnancy experience more broadly. We urge future researchers to engage with more diverse identities and experiences and to consider recruiting through different social technologies in order to better understand LGBTQ pregnancy loss disclosure decisions on other platforms.

\section{RESULTS}

In this section we report on the factors influencing (non)disclosure decisions for LGBTQ participants who experienced pregnancy loss, situating these results within the Disclosure Decision-Making (DDM) framework. In many cases, one's LGBTQ identity uniquely shaped one or more factor types considered by the DDM framework to drive disclosure decisions. We conclude by describing perceived ideal characteristics of social media platforms that would facilitate 
Table 1: Participants' Aggregated Sociodemographic Data

\begin{tabular}{|c|c|}
\hline Factors & Mean (SD) or N (Proportion) ${ }^{\mathrm{a}}$ \\
\hline \multicolumn{2}{|l|}{ Pregnancy loss experiences } \\
\hline \multicolumn{2}{|l|}{ Pregnancy loss experience } \\
\hline Physically experienced pregnancy loss & $14(82.4)$ \\
\hline In an intimate partnership in which pregnancy loss occurred & $3(17.6)$ \\
\hline \multicolumn{2}{|l|}{ Year in which pregnancy loss occurred } \\
\hline 2019 & $4(23.5)$ \\
\hline 2018 & $8(47.1)$ \\
\hline 2017 & $5(29.4)$ \\
\hline \multicolumn{2}{|l|}{ Sociodemographic characteristics } \\
\hline Age & 34.4 (3.3), Range: 29 to 40 \\
\hline \multicolumn{2}{|l|}{ Gender identity } \\
\hline Cisgender woman & $15(88.2)$ \\
\hline Transmasculine person & $1(5.9)$ \\
\hline Non-binary person & $1(5.9)$ \\
\hline \multicolumn{2}{|l|}{ Sexual orientation } \\
\hline Lesbian & $3(17.6)$ \\
\hline Bisexual & $1(5.9)$ \\
\hline Queer & $5(29.4)$ \\
\hline Asexual (biromantic, demiromantic) & $2(11.8)$ \\
\hline More than 1 sexual orientation (e.g., Lesbian/Queer, Bisexual/Queer) & $6(35.3)$ \\
\hline \multicolumn{2}{|l|}{ Race/ethnicity $(\mathrm{n}=16)$} \\
\hline White & $13(76.4)$ \\
\hline Black/African American & $1(5.9)$ \\
\hline Latinx & $1(5.9)$ \\
\hline Multiple races/ethnicities & $1(5.9)$ \\
\hline \multicolumn{2}{|l|}{ Relationship } \\
\hline Partnered & $16(94.1)$ \\
\hline Single & $1(5.9)$ \\
\hline \multicolumn{2}{|l|}{ Education } \\
\hline College & $4(23.5)$ \\
\hline Graduate Degree & $13(76.4)$ \\
\hline \multicolumn{2}{|l|}{ Income } \\
\hline$\$ 1,000-\$ 29,999$ & $2(11.8)$ \\
\hline$\$ 30,000-\$ 49,999$ & $1(5.9)$ \\
\hline$\$ 50,000-\$ 74,999$ & $4(23.5)$ \\
\hline$\$ 75,000+$ & $10(58.8)$ \\
\hline \multicolumn{2}{|l|}{ Religion } \\
\hline Nothing in particular & $9(52.9)$ \\
\hline Agnostic & $2(11.8)$ \\
\hline Jewish & $2(11.8)$ \\
\hline Unitarian Universalist & $1(5.9)$ \\
\hline Protestant & $1(5.9)$ \\
\hline Multiple religions & $2(11.8)$ \\
\hline \multicolumn{2}{|l|}{ Geography } \\
\hline Urban & $14(82.4)$ \\
\hline Rural & $3(17.6)$ \\
\hline \multicolumn{2}{|l|}{ Social media use } \\
\hline \multicolumn{2}{|l|}{ Online platforms used (non-pregnancy-related) $\mathrm{b}$} \\
\hline Facebook (not Facebook support groups) & $17(100.0)$ \\
\hline Facebook support groups & $12(70.6)$ \\
\hline Instagram & $12(70.6)$ \\
\hline Twitter & $4(23.5)$ \\
\hline Reddit & $2(11.8)$ \\
\hline Snapchat & $1(5.9)$ \\
\hline \multicolumn{2}{|l|}{ Social media disclosures } \\
\hline \multicolumn{2}{|l|}{ Disclosed/shared pregnancy loss online } \\
\hline Yes & $10(58.8)$ \\
\hline No & $7(41.2)$ \\
\hline \multicolumn{2}{|l|}{ Disclosed/shared sexual orientation/gender identity online $(n=16)$} \\
\hline Yes & $16(100.0)$ \\
\hline No & $0(0.0)$ \\
\hline
\end{tabular}

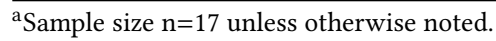

${ }^{\mathrm{b}}$ Response options not mutually exclusive. 
Table 2: Disclosure Decision-Making Framework explains disclosures on social media involving intersectional stigma for LGBTQ people experiencing pregnancy loss

Factors related to (non)disclosures of stigmatized experiences on social Examples from the present study

media

Self-related

(Non)disclosure decisions relate to the self, including one's personality and self-help mechanisms

\section{Audience-related}

(Non)disclosure decisions relate to the control of personal information and concerns over audience reactions and needs

\section{Network-related}

(Non)disclosure decisions relate to perceptions of stigma in one's network and one's perception of how different they are from members of their network

\section{Societal}

(Non)disclosure decisions relate to perceptions of broader societal stigma

\section{Platform and Affordance-related}

(Non)disclosure decisions relate to the specific features and affordances of social media platforms, such as anonymity, asynchronicity, and disclosure norms
"I knew that it was going to come up and I was like, 'So why am I not just mentioning it now?' Like, 'I need support. I need my community. These people I'm connected with are that."' $(\mathrm{P} 4)$ "I tend to be a very private person in general. I'm not a very active user of social media. I tend to kind of even in person, I tend to kind of keep my cards close to my vest, except with people that I'm really close with." (P7)

“...All of those questions are intrusive and inappropriate and mentioning a loss brings up all of the same questions about how'd you get pregnant in the first place? Where'd you get the sperm?" (P5)

"So I think my goal is certainly to make it better for LGBT people to be able to talk about this and feel like they have community and information around it." (P9)

"...if I had been just like sharing about it all along, and had seen there are people in my circle who have been really, really public and vocal about their whole process, I think by the time I did experience the pregnancy loss, five years into the process it just felt like too much to, like how do you share that in a post?" (P12)

"I feel like my decision to want to share was associated with my identity as a queer person. . Because I want people to be aware. Oh it's not like we can accidentally get pregnant or we just whatever, have sex and then it happens, I feel like there's a lot of intentionality and a lot of hardship that queer couples go through to conceive” (P14)

"Knowing that anyone could access that, even though they probably wouldn't? Like I think about people Googling me if I'm looking for a new job or something. And I have my Facebook setting set to private, but I still feel like that kind of stuff can get out there...” (P3) sensitive disclosures for LGBTQ individuals experiencing intersectional stigma.

\subsection{Disclosure Decision-Making Framework Explains LGBTQ Participants' Pregnancy Loss Disclosure Decisions to Known Ties on Social Media}

Our analysis suggests that the DDM framework [4] is comprehensive in explaining the types of factors that inform disclosures of stigmatized experiences. In addition to explaining the disclosure decisions of cisgender women who experienced pregnancy loss [4], the primary types of factors (self-related, audience-related, network-level, societal, and platform and affordance-related) also shaped disclosure decisions of LGBTQ participants who experienced pregnancy loss, albeit sometimes in unique ways particularly related to the LGBTQ identity. This is important because we can move one step closer to developing theories of online disclosure that span contexts and populations.

4.1.1 Self-Related Factors Contributing to (Non)Disclosure Decisions. Participants described self-related factors contributing to their disclosure decisions that mapped onto the DDM framework. Self-related factors, including taking control of the parenthood narrative and eliciting social support, contributed to the decision to disclose. For example, P4 said: "It didn't feel right not talking about it, because it had become such a huge part of my story. It had 
become, like I knew not mentioning it was going to mean that I had ... that I didn't share part of my future story.” By sharing their loss as part of their overarching parenthood narrative, this participant was able to regain some control which is often lost in the aftermath of pregnancy loss. This participant attributed their disclosure to a desire to elicit social support: "I knew that it was going to come up and I was like, 'So why am I not just mentioning it now?' Like, 'I need support. I need my community. These people I'm connected with are that."' This participant recognized that their social network, consisting of friends, members of a LGBTQ-specific postpartum Facebook group, and other LGBTQ and feminist connections, could provide them with much-needed social support in the aftermath of a traumatic pregnancy loss experience, and disclosed as a means to receive this support. That said, had they not anticipated this support, they would have likely not disclosed due to concerns related to audience responses.

While many participants described self-related factors that contributed to the decision to disclose, some participants described self-related factors that led to non-disclosure. Some participants who did not disclose, such as P7, attributed this decision to the fact that they are a more private person in general and online: "I tend to be a very private person in general. I'm not a very active user of social media. I tend to kind of even in person, I tend to kind of keep my cards close to my vest, except with people that I'm really close with." Similarly, P17 reported: "I'd say, I guess, I'm a fairly private person in general. I don't go out of my way to tell a lot of people a lot of information that really isn't relevant to them." These participants' tendency to be reserved in sharing personal information, not only influenced their face-to-face communication but also their communication on social media broadly and in relation to pregnancy loss. Furthermore, individual preferences for processing a stigmatized experience influenced non-disclosure decisions. P7 revealed:

"I think that maybe [non-disclosure] helps me process quicker, because I really had to rely on myself. I did a lot of personal reflection, and I think in some ways, like really having to sit with those feelings made me process through them and deal with them in a way that I wouldn't have had I been able to just kind of live in the space of loss and continue talking about the mechanics of it or like start those feelings about it. Getting positive feedback for that might have caused me to become more stuck in it rather than being able to move beyond."

For this participant, the feedback that disclosure would elicit would impede their processing of the loss, which relies on internal reflection.

4.1.2 Audience-Related Factors Contributing to (Non)Disclosure Decisions. Several participants revealed that their LGBTQ identity shaped the responses they anticipated receiving if they disclosed their pregnancy loss on their personal social media pages. These anticipated responses, in turn, influenced their decision not to disclose their loss experience. The participants in this study highlighted experiences of enacted stigma, such as invasive questions linked to their LGBTQ identity that could be asked in response to pregnancy loss disclosures. For instance, P5 described some of the hurtful and invasive questions that could be asked of them if they disclosed their pregnancy and loss as an LGBTQ person on social media:

"Anytime you talk about one of these issues with cis people that never have to think about this stuff, whether it's the fact that I'm trying for kids or the fact that I'm trans, they start, certain subsets of people anyway ask intensely personal medical questions, everything from the hormones that I'm on to what surgeries I might want or not want, to what my genitals look like to how we have sex to who's providing the sperm for our baby. All of those questions are intrusive and inappropriate and mentioning a loss brings up all of the same questions about how'd you get pregnant in the first place? Where'd you get the sperm?"

This quote exemplifies both enacted stigma, whereby the participants experienced negative interactions with peers, while also increasing felt normative stigma whereby participants seeking pregnancy support expected such questions.

Engaging in social interactions where one's LGBTQ identity is questioned or medicalized or where one's privacy is invaded leaves LGBTQ individuals with the burden of educating others which can be exhausting [78], or risk experiencing other harm such as feeling unseen or invalidated. Thus, some choose to preemptively protect themselves against such harm. The DDM framework [4] considers anticipated audience responses as audience-related factors that contribute to non-disclosure [2]. Specifically, the DDM framework considers the desire to avoid questions to be a primary factor influencing non-disclosure decisions [2]. The desire to avoid questions is also a reason for non-disclosure found among cisgender heterosexual people who experienced pregnancy loss [4], but this quote illustrates the ways that one's LGBTQ identity compounds and complicates the anticipated responses that influence non-disclosure decisions of loss on social media.

In addition to invasive questions, participants also reported that they anticipated discriminatory and hurtful comments (enacted stigma) specifically related to their LGBTQ identity, emphasizing the way that their LGBTQ identity was inextricably linked to audience-related factors contributing to their non-disclosure decisions. Participants such as P10 revealed:

"Definitely seen just general things like re-sharing of memes that are anti-inclusion...So they're definitely not afraid of saying those things...So I'd be concerned that, if we ever announced that we were pregnant, that they would think that was unethical. If they found out we've lost a pregnancy, they would think that was God saving the baby."

This excerpt illustrates not only that one's LGBTQ status influences the types of hurtful comments they may receive in response to a disclosure, but also illustrates that these anticipated hurtful responses are often grounded in past experiences of witnessing or being directly harmed by homophobia and transphobia from members of their social media network, such as through seeing others' shared content. In discussing why this audience-related factor led to non-disclosure, P10 explained: "I don't want to have to deal with people telling me that it's my fault that it happened. Which I think people would normally say to straight people, but I 
think would be more likely to say to people that are not straight." This participant is clearly identifying the felt normative stigma associated with pregnancy loss, which can become internalized, as well as how such stigma associated with loss may be exacerbated for LGBTQ people. People who experience pregnancy loss often blame themselves for their loss, and sometimes other people blame them as well, including their children and partners [21, 87]. This participant's quote reveals the perception that the tendency for others to assign blame to the person who experienced loss is heightened if the person who experienced the loss is LGBTQ. Whether or not LGBTQ people statistically receive more blame, LGBTQ people's perceptions about anticipated responses shape their loss (non)disclosure decisions.

4.1.3 Network-Level Factors Contributing to (Non)Disclosure Decisions. An LGBTQ identity also shaped the desire to serve as a source of support for others in one's network who may have gone through or will go through pregnancy loss, which is a network-level factor (in DDM's terms) [4] contributing to disclosure. For instance, P9 described the desire to specifically support other LGBTQ people dealing with loss: "So I think my goal is certainly to make it better for LGBT people to be able to talk about this and feel like they have community and information around it." This participant wanted to disclose their loss in order to provide social support to similar invisible others within their network who may experience or have experienced their own pregnancy loss. They also wanted to disclose in order to inspire other disclosures from those within their networks to combat stigma associated with LGBTQ pregnancy loss, thereby encouraging what Andalibi and Forte call network-level reciprocal disclosures [4]. For instance, P7 says: "I kind of just hope to be one of the crowd saying, yep, you're not alone. This really does suck. But there are people out here who get it, and this is a safe place to share”. Similarly, P4 says:

"But it's so much of a common experience, and I think I want people to talk about it more because I want people to know they're not alone when they are going through it. I think the only way you do that is by being the change you want to see."

Disclosure constituted one way that participants could show others who have experienced undisclosed loss that they were not alone, and that social media could be a safe space in which to disclose, if they wanted to.

Network-level factors contributed to non-disclosure decisions as well. Some participants attributed non-disclosure to the difficulty in summing up their unique pregnancy journey as an LGBTQ person. This difficulty is exacerbated by the fact that many participants had not seen another LGBTQ person in their network disclose their loss before. When asked about what might have influenced them to disclose, $\mathrm{P} 12$ reported:

"I think for me I had not shared about my trying to conceive journey at all on social media. It felt like a lot to ... it felt like too much, and too vulnerable to not only come out about, like having had a miscarriage, but also the fact that I was even trying to get pregnant, that just felt like too much. I think for me personally, if I had been just like sharing about it all along, and had seen there are people in my circle who have been really, really public and vocal about their whole process, I think by the time I did experience the pregnancy loss, five years into the process it just felt like too much to, like how do you share that in a post?"

Not only was this participant personally comfortable with nondisclosure of their pregnancy journey on social media (a selfrelated factor contributing to nondisclosure), but the fact that they had not seen anyone else in their network share about having a similar experience (a network-level factor) further cemented their decision not to disclose.

4.1.4 Societal Factors Contributing to (Non)Disclosure Decisions. An LGBTQ identity contributed to the desire to be visible to bring awareness to LGBTQ pregnancy and pregnancy loss, constituting a societal factor contributing to disclosure decisions. When asked how their identity influenced their disclosure decision, P14 explained:

"I feel like my decision to want to share was associated with my identity as a queer person. . . Because I want people to be aware. Oh it's not like we can accidentally get pregnant or we just whatever, have sex and then it happens, I feel like there's a lot of intentionality and a lot of hardship that queer couples go through to conceive. That for me feels really important to be open about that journey, so the desire to wanna be open about every part of the journey including a miscarriage felt propelled by the fact that I'm queer."

Similarly, P6 said:

"If I didn't talk about it, if I didn't talk about what we were doing, and doing IVF and all this kind of stuff, people wouldn't know that's ... I also just want to model that idea of same-sex couples are also allowed to get pregnant and to want to be pregnant, and to want to have that experience. That's something that we're allowed to do...I was wanting to normalize the idea of pregnancy as a queer experience."

Participants wanted to bring awareness to and normalize LGBTQ pregnancy by sharing their larger pregnancy journeys, which included sharing stories of pregnancy losses. Beyond this, participants also wanted to shift others' perceptions about LGBTQ folks' fundamental reproduction desires. This desire to "normalize" pregnancy among LGBTQ people was one manifestation of felt normative sexual stigma. According to the Disclosure Decision-Making framework [4] disclosure to educate and bring awareness is considered a societal factor contributing to disclosures of stigmatized experiences on identified social media. This societal factor, according to participants, was directly shaped by their LGBTQ identity.

4.1.5 Temporal Factors Contributing to (Non)Disclosure Decisions. Participants also described temporal factors that influenced their disclosure decisions. Participants described that the passage of time helped encourage disclosure. Conversely, being too temporally close to the loss actively discouraged disclosure, as participants' emotions were too raw. Describing this temporal dynamic, P5 said: 
"It was a product of, it's been enough time and we've been open enough with people here that they know that we're trying so we don't have to worry about keeping that secret to the same extent. And it was the one-year anniversary of the due date with my pregnancy so when our baby would have been turning one, and I just, I wrote a thing processing my feelings of that and posted it publicly on my Facebook wall. Well not full publicly, but to friends".

Disclosure did not happen until sufficient time had passed, allowing participants to privately work through their raw emotions before disclosing to their network. P9 referenced the possibility of a future disclosure: "What I think about more so now is that when hopefully I do have a child, maybe that will be a time when in sharing that news I can share some of that story." This quote reveals that the passage of time may help people move through the loss because with time they can have another child. Once they move through the loss, they may feel more comfortable disclosing it.

4.1.6 Platform and Affordance-Related Factors Contributing to (Non)Disclosure Decisions. Finally, certain platform and affordancerelated factors discouraged LGBTQ participants from disclosing their experiences with loss on social media. Specifically, a perceived lack of control over one's private information informed non-disclosure decisions. Even with the ability to manipulate privacy settings on platforms like Facebook, P3 described lingering privacy concerns that prevented them from disclosing:

\begin{abstract}
"Knowing that anyone could access that, even though they probably wouldn't? Like I think about people Googling me if I'm looking for a new job or something. And I have my Facebook setting set to private, but I still feel like that kind of stuff can get out there...”
\end{abstract}

Whether or not one's information is protected or not in practice is not relevant here; rather, we see that the worry that their information will be available to unintended audiences was a barrier to disclosure on social media. Perceptions about the norms of disclosure on a social media site also led to non-disclosure, particularly for those who felt that such a personal disclosure violated site norms. For instance, P13 described:

"Yeah, so I don't treat it [personal social media profile] like a blog most of the time... Like, I don't tend to talk about my life very much. And so it feels like a weird forum for me to share a super personal experience. I mean, anything beyond like, 'Oh, it's spring today and that's awesome because I was so tired of winter....I mean, it's like that kind of thing. It's just not the kind of place where you share."

The perception of Facebook as an inappropriate venue for sharing deeper, more personal information hindered participants from disclosing their pregnancy loss on the site.

\subsection{Ideal Online Environment for Pregnancy Loss Disclosures on Social Media for LGBTQ People}

Our analysis revealed several qualities of ideal disclosure environments for LGBTQ people experiencing loss, including platforms that allow one to disclose to subsets of their network, platforms that provide advice and education on how to support those dealing with a loss, and platforms that move beyond positivity bias [89, 102-104] and promote true, honest exchange.

Some participants wished to disclose selectively to subsets of their networks, to pre-existing ties and/or to close ties. For example, when asked about an ideal social media platform for disclosure, P10 said: "I guess ideally for me, would be made of people I know already." Echoing this sentiment, $\mathrm{P} 11$ proclaimed: "I think the preexisting community is key. I don't think I could have just walked into a new group and been as comfortable being as bare-bones honest as I needed to be in order to get anything from it." Some participants not only wanted the ability to disclose selectively to pre-existing ties, but also wanted the ability to disclose selectively to close ties. For instance, when asked what parts of the online environment would make it easier for people to disclose sensitive experiences like pregnancy loss, P15 emphasized the importance of being able to disclose specifically to close friends:

"So, like I can start by just telling that group of them or some of my close friends who don't know, but who I would feel comfortable telling. Because I do. I do think in life, generally, being as transparent and vulnerable and relatable as possible is good. And I think society generally would benefit from that."

Conversely, P11 acknowledged that the ability of non-close ties to see a sensitive disclosure was a factor that prevented them from disclosing:

"I think there's just factors in other areas of my life that prevent me from wanting to share that publicly. I mean, like I said, there is some things that I'm very public about, like my job and the fact that I am a lesbian and my family. But there were some people in my life that I hadn't shared with that we were trying or that we were thinking about it."

A platform that enables selective disclosure either to pre-existing or close ties would obviate this audience-related preventative factor (in DDM's terms) and enable sensitive disclosures to safely take place.

Additionally, participants described an ideal platform for disclosure that would educate and advise audience members about LGBTQ pregnancy loss and how to use supportive language. For example, P14 proclaimed: "I feel like if people were aware of how to provide support or words of comfort for people that are going through something like miscarriage, then people would be more able to be open about their experience." A platform that educates and advises users would help to curb the fear of a stigmatizing response, thereby reducing this audience-related fear as a barrier to disclosure. Elaborating on factors that would have made disclosure easier for them, P6 said: 
"I think not having to be the teacher every single time I talk about any of this stuff would have made my experience easier... I think that that's pretty much the biggest thing that would have made any of this easier, was just having people ... not having to explain and teach people about my grief, but just being able to express it."

This participant revealed that LGBTQ people frequently are burdened with the task of educating others in their network who make invasive, invalidating, or hurtful comments and are generally ignorant. Interventions that educate and advise audience members on ways to appropriately support the person who had disclosed their loss would encourage disclosure by relinquishing LGBTQ people from the labor of educating their network about LGBTQ pregnancy and loss.

Finally, participants indicated that for true and honest exchanges around sensitive disclosures to take place on social media platforms, we must move beyond the tendency to only or primarily post positive content that is endemic to many prominent commercial social media platforms. P15 describes this tendency and the impact it has on the ability of a platform to facilitate disclosures, saying:

"I mean, I think one of just the problems of social media generally...this isn't always the case, but generally speaking it tends to be a forum where you put your best foot forward. You show all the good things that are happening, putting the good photos up, the good parts of your day, the good parts of your life, the fun things that you're doing. It's generally not a forum for like true exchange."

It is important to note the use of the term "true exchange" here, highlighting how participants found it difficult to engage in what feels true to them on social media. Similarly, P14 indicates:

"I think that there's this thing that happens on Facebook or Instagram, where people for the most part wanna just share all the great things that are happening in their life and there isn't any vulnerability or openness around how difficult life can be sometimes. If there were more open and honest conversations about people struggling, whether with mental health, with their life goals, with miscarriage or even the fertility journey, I think that would make me feel inspired and comfortable in sharing my personal experience with miscarriage."

These participants acknowledge a positivity bias, or the tendency for social media environments to favor positive self-presentation over negative or perhaps more authentic self-presentation, as a barrier to disclosure and effective social support exchange [89]. Prior work suggests not only that users prefer to disclose positive forms of self-presentation on social media [89], but also that positivity is more appreciated by the social media audience [12]. Thus, when one needs social support around a stigmatized life experience, especially if they possess other marginalized and stigmatized identity facets described here (e.g., being LGBTQ), it is difficult to both disclose this experience and get support around it because it violates perceived site norms.

\section{DISCUSSION}

In this paper, we extend the utility of the Disclosure DecisionMaking (DDM) framework [4] to explain LGBTQ pregnancy loss disclosure decisions when facing intersectional stigma and an understanding of the ways in which LGBTQ identity influences (non)disclosure decisions. We also contribute characteristics of perceived ideal social media disclosure environments for LGBTQ persons who experienced pregnancy loss. In summary, opportunities for disclosure to networks of known ties are not equal for all individuals enduring pregnancy losses, and LGBTQ people face unique challenges in doing so as we have described. While these findings were related to the disclosure of pregnancy loss by LGBTQ people, we suggest that they could extend to disclosures of other stigmatized experiences by people with one or multiple stigmatized or otherwise marginalized identity.

Next, we discuss the Disclosure Decision-Making framework and how it complements other theoretical frameworks that have been used to explain disclosure decisions and processes. Then we provide implications for design.

\subsection{Intersectional Stigma on Social Media: Extending and Complicating Self-Disclosure Frameworks}

Several communication theories and frameworks have considered disclosure, or the deliberate revelation of personal information to others [46], to be a key communicative process and seek to understand how disclosure decisions are made. For instance, Omarzu's Disclosure Decision Model [81] suggests that the disclosure decision-making process consists of three stages, including pursuit of a social goal, selection of a strategy and target for the disclosure, and a subjective risk and utility assessment. Chaudoir and Fisher's [25] Disclosure Processes Model considers disclosures made by people with concealable stigmatized identities and suggests that antecedent goals influence whether or not a disclosure event takes place. These theories and frameworks have historically examined dyadic face-to-face disclosures. Andalibi and Forte's Disclosure Decision-Making framework [4] builds on Omarzu's as well as Chaudoir and Fisher's frameworks by foregrounding computermediated disclosure processes, which often consist of one-to-many disclosures through status updates. In doing so, it overtly considers digital platforms' sociotechnical contexts and affordances as factors that shape (non)disclosure decisions. In this study, we showed how the Disclosure Decision-Making framework [4] helps explain the disclosure decisions made by LGBTQ individuals experiencing loss, providing support for this framework's value in explaining disclosures through an intersectional stigma [95] lens. Pregnancy loss is not the only stigmatized experience that LGBTQ people cope with; further, LGBTQ people are not the only individuals who experience intersecting stigma for whom disclosure poses unique challenges. Our analysis and complicating of previous disclosure frameworks provide a useful setting to analyze disclosure decisions to networks of known ties on social media for other individuals experiencing intersecting stigmas, such as women of color who experience interpersonal violence, LGBTQ people who have HIV, and refugees who experience mental illness. Disclosure research in contexts such as these would benefit from an intersectional 
approach that incorporates methodologies outlined by McCall [71] or invokes the concept of intersectional stigma [95] as we did in the present study to inform the design of more inclusive online spaces.

\subsection{LGBTQ Identity Influences Pregnancy Loss Disclosure Desire and Decision on Social Media}

We found that one's LGBTQ identity shaped the desire to disclose experiences with loss to networks of known ties on social media. Participants desired to disclose experiences with loss to bring awareness to LGBTQ pregnancy and loss and to support other LGBTQ people experiencing pregnancy loss. Because there are so few resources that explicitly acknowledge and support LGBTQ people experiencing pregnancy loss, participants desired to be open about their own experience to support others in their network who may have experienced a loss or may experience one in the future. Furthermore, the dominant narrative around pregnancy centers cisgender, heterosexual women [24, 60, 64] (as also noted by participants in our study), which explains the lack of awareness even among health care professionals involved in fertility treatments and pregnancy-related check-ups who make heterosexist and cisnormative presumptions to their LGBTQ patients [24, 60, 64]. In response, LGBTQ people experiencing pregnancy loss desired to disclose experiences with loss to bring awareness to LGBTQ pregnancy and loss, in the hopes that more awareness may mean that future LGBTQ pregnant people will not experience invalidating hetero-normativity and cis-normativity. Overall, the finding that one's LGBTQ identity influences the desire to disclose experiences with pregnancy loss suggests that marginalized people have more of an impetus to disclose because they feel responsible for producing counternarratives that challenge dominant narratives about their communities. However, there exists a tension between wanting to disclose and not feeling safe enough to do so, for reasons we discuss next.

One's LGBTQ identity also influenced anticipated stigmatizing, hurtful and invasive audience reactions, which ultimately prevented some participants from disclosing on their personal social media pages. Prior literature has frequently found that a fear of homophobic, discriminatory reactions prevents LGBTQ folks from disclosures related to their LGBTQ identity in myriad contexts ranging from the workplace to health care situations $[18,88]$. Previous health care studies show that in in-person settings, witnessing past anti-LGBTQ rhetoric and heterosexist assumptions from thxe potential audience of the disclosure leads to non-disclosure of one's sexual identity among LGBTQ people [39]. Here we uncover the unique challenges LGBTQ people face in relation to disclosing experiences of loss and seeking support on social media. Our findings echo the larger body of literature involving LGBTQ individuals and their social media use, which documents challenges related to the disclosure process and stress about the lack of control over online disclosures [15, 49]. Not only do LGBTQ people face challenges in disclosing their LGBTQ identities online, but they also face challenges in disclosing intersecting stigmatized experiences online. Social media platforms should create safe spaces for LGBTQ people, free of hurtful experiences. Otherwise, they do marginalized users a disservice because these users constantly have to fear hurtful responses, which in turn compromises their ability to disclose and receive social support.

\subsection{Design Implications}

Next, we outline design insights based on participants' descriptions of ideal disclosure environments. While these features may promote disclosure for LGBTQ people experiencing pregnancy loss, they also carry substantial privacy risks. Thus, our design implications are suggestions that should be further augmented before implementation. While some are speculative, we find value in imagining alternatives to existing designs.

5.3.1 Enabling Selective Disclosure to a Subset of One's Social Media Network. Context collapse is a phenomenon that occurs on social network sites like Facebook when multiple distinct audiences in one's network are "flattened out" so that members of these distinct audiences become one large group of message recipients [69]. Many LGBTQ participants were concerned about certain segments of their social media audience and the responses they may receive from them if they disclosed their loss. Thus, context collapse increased risks associated with disclosure and often contributed to non-disclosure decisions for this population.

Interventions may seek to uncover those in one's network who may share similar identities and experiences, operating under the assumption that those with shared experiences and identities are more likely to provide socially supportive responses to disclosures. Participants in this study reported wanting to disclose selectively to close ties and pre-existing or known ties. While Facebook possesses a list feature for selective disclosure, this feature is labor-intensive and infrequently used [42]. A label feature on identified platforms like Facebook may enable and encourage people to selectively disclose. Facebook has already demonstrated its ability to develop a feature in which a label indicating what someone has in common with a user outside of their network appears alongside the user's name [79]. In this case, similar labels could be assigned to individuals within one's network. By restricting the labels to only those within one's network, ensuring that all parties involved must opt-in to use the feature, and only showing labels that individuals have in common, this design element could help users identify those who may be more supportive upon receiving the disclosure while protecting user privacy.

For LGBTQ people who experience pregnancy loss, this could mean that they can disclose to other LGBTQ people in their network or other people in their network who experienced pregnancy loss, either in a one-to-one or one-to-many fashion. Since some LGBTQ users already manually create lists on Facebook to control disclosure audiences [49], integrating a label feature with the preexisting list feature could be a welcome change which limits the amount of labor marginalized users have to perform on social media platforms when disclosing stigmatized identities or life experiences to multiple individuals simultaneously. A label feature may even encourage the many social media users who previously had not used the (previously labor-intensive) list feature [42] to do so to meet their selective disclosure needs. Still, there would be understandable concerns with technology companies like Facebook having access to data related to identities and sensitive experiences, and these concerns may prevent users from embracing the feature, for 
example if they are used to serve the company rather than the user such as through targeted advertising or sharing this sensitive data with third parties. Without regulation via policy the label feature would primarily serve the interests of platforms which are agents of surveillance capitalism and data colonialism, systems that rely on behavioral data for its perpetuation [30, 105]. Moreover, editable labels enable users to add false labels to their own profile to see who in their network uses that label. This can lead to the leakage of personal information to hostile actors. However, while labels that are static in nature may circumvent this challenge, they do not reflect the dynamic nature of identity. Furthermore, LGBTQ users' use of Facebook lists to control their LGBTQ identity disclosures' audience is stressful [49], and it remains unclear whether reducing the labor required to segment one's audience would mitigate or exacerbate this stress. As such, any such intervention should be done carefully and hand in hand with policy and regulation change with input from data subjects.

5.3.2 Allowing a Proxy Comment Moderator. Participants described anticipated negative audience reactions as a factor impeding their ability to engage in desired disclosures on identified social media platforms like Facebook. To help minimize negative responses, designers could allow users to appoint a proxy to moderate comments made in response to sensitive disclosures. In contrast to prior work which suggests that proxies make disclosures on behalf of the person who experienced pregnancy loss [8], the role of a proxy in this instance is to moderate responses to disclosures made directly by the person who experienced pregnancy loss. "Friendsourced moderation" tools have already been suggested as one way to combat online harassment, albeit in the context of email harassment [68]. These tools, like Squadbox, allow a group of friend moderators to "intercept email from strangers" and "reject, organize, and redirect emails" [68]. Similarly, albeit in an identified social media context, proxy moderators would review each comment received in response to a sensitive disclosure and determine if and when a comment would be published and become visible to the original poster. These moderators may be relationally close to the discloser, so they may have more knowledge on what types of comments would be particularly supportive and what types of comments would be potentially triggering. Human moderators would potentially have a more nuanced understanding of the discloser's desires, needs, and triggers than an artificial intelligence moderation system. They could allow supportive comments to reach the person who experienced pregnancy loss while preventing this person from being negatively impacted by hurtful, judgmental, or insincere comments. Furthermore, a human moderator can possess knowledge of when the person who experienced pregnancy loss is too hurt to engage and can prevent comments from being published until the original poster is emotionally ready. Overall, a proxy moderator feature can provide a way for allies to actively support their LGBTQ friends and family who experience pregnancy loss. While this feature is promising, there may be negative consequences for the discloser if their relationship with the proxy moderator ruptures. There are also surely security risks, as hackers can access and compromise sensitive information via multiple accounts as opposed to only the discloser's account. Because proxy moderation is fundamentally a collaborative activity, design of this feature should be approached from the perspective of both the discloser and the proxy and should consider privacy and security risks for both parties.

5.3.3 Advising and Educating Social Media Audience Members about LGBTQ Pregnancy Loss. Participants reported wanting social media platforms to actively advise and educate their users about topics, like pregnancy loss, that they may see discussed in their feeds. Prior work on digital health education interventions suggests that health education interventions be incorporated into existing, popular platforms [19]. Facebook and Instagram have already demonstrated their ability to incorporate health education interventions into their platforms in the wake of COVID-19 through Facebook's COVID-19 Information Center [54] and Health \& Wellness Guides on Instagram [106]. A Pregnancy Information Center could be relevant and helpful since pregnancy announcements are made on the platform. This information center would ideally be available to users yearround, but Facebook may highlight them by placing them on the top of news feeds in June (Pride Month) and October (Pregnancy Loss Awareness Month) like they did with the COVID-19 Information Center [54]. Furthermore, medical experts could work with Facebook to curate fact-checked and peer-reviewed information about pregnancy as well as pregnancy loss and display it on the Pregnancy Information Center. In this way, Facebook users would put their trust in the hands of medical experts as opposed to technology companies alone. Such an intervention must be inclusive of all identities, providing information for LGBTQ people who are historically left out of Western pregnancy and loss narratives. Similar to Facebook's COVID-19 Information Center, it can include requests and offers for help from members of one's geolocated community. The Pregnancy Information Center could also include requests and offers for help from members of one's Facebook network, consisting of people who may not live near each other. Because pregnancy and loss are sensitive topics, users should be able to control who is able to view their requests for help or offers for help. Specifically, users should be able to limit who views their requests or offers to known ties, or their Facebook Friends. Thus, they can take advantage of the Pregnancy Information Center as a site of social support exchange without compromising their privacy. By encouraging both one's geolocated community and one's Facebook network to exchange help and resources, LGBTQ people can benefit from various types of social support (instrumental support, informational support, emotional support, and esteem support) [35]. Significantly, a Pregnancy Information Center can provide a digital space wherein allies who wish to aid LGBTQ people can offer pregnancy and loss-related support and education to their local community and Facebook network. This way, it is not just up to LGBTQ people who experience loss to exchange support with each other, although that is a complementary and necessary component of coping [70]. Rather, allies who engage in these types of supportive behaviors can play a substantial role in offering support that is integral to wellbeing in the wake of pregnancy loss as well as education that can mitigate future negative comments aimed at LGBTQ people who experience pregnancy loss.

5.3.4 Prioritizing Sensitive Disclosures in Social Media News Feeds. Participants described an ideal online platform for disclosure as one that would promote what they considered to be "true" and "honest" 
exchange. They desired a space to broadcast and discuss experiences and identities that were laden with negative emotion, as they perceived this to be more authentic. One way that platform designers can encourage perceived true and honest exchange is through an updated news feed algorithm. Facebook news feed algorithms have shifted considerably since the invention of the news feed in 2006 and the invention of the news feed sorting algorithm in 2009 [107]. In the future, designers could create a news feed algorithm that prioritizes disclosures of personal or sensitive information by ensuring that they appear more often and more prominently on users' feeds. This algorithm could encourage further disclosures by shifting the norms about disclosure on the site and could even help to reduce stigma (through increasing desired visibility), another barrier to disclosure that LGBTQ folks who experienced pregnancy loss reported. While this algorithm would increase the visibility of personal and sensitive disclosures and has the potential to be beneficial [1] such as to those desiring visibility or those who seek similar others, it is necessary to note that visibility can also be harmful, especially when those to whom the disclosure is visible are unsupportive or when the shared data is used in ways opaque or undesirable to the poster (e.g., targeted advertising drawing on one's vulnerability [17]). Visibility can facilitate the disproportionate distribution of risk and harm to marginalized users, both those who disclose and those who view disclosures. It can lead to stigmatizing responses and can trigger disclosure recipients [5]. Further, the prioritization of sensitive disclosures in social media news feeds necessitates the use of computational methods to discern the disclosure by social media companies, but social media users are skeptical towards inferences based on such data [3]. Thus, users may rightly react adversely to the transparent prioritization of sensitive disclosures - and we advocate that they should be transparent, but that discussion is outside the scope here - and as such users should opt-in rather than opt-out of the feature. Features that enable selective disclosure, proxy comment moderators, and pregnancy loss education must be paired with news feed algorithms to ensure that disclosures are visible to those most likely to be supportive, such as closer ties or those demographically similar to the poster (in this instance, LGBTQ folks and folks who have experience with pregnancy or loss). By grouping these features together, the overarching intervention could simultaneously take into consideration issues around context collapse and ignorant or insensitive feedback, effectively promoting beneficial and safe disclosure of stigmatized experiences.

\section{CONCLUSION}

This work extends the Disclosure Decision-Making (DDM) framework [4] to those experiencing intersectional stigma by focusing on LGBTQ identity and pregnancy loss as the central context of inquiry within a context of cisnormativity, heteronormativity, and patriarchy. It also contributes an understanding of how one's LGBTQ identity influences DDM decision factors that drive (non)disclosure decisions on social media. Next, this work describes ideal online environments which could facilitate beneficial disclosures for those experiencing intersectional stigma, informing design implications. Finally, we describe four distinct interventions which could be incorporated into identified social media platforms to better facilitate beneficial disclosures by LGBTQ people experiencing pregnancy loss. While this population faces increased barriers to disclosure, social media designers can incorporate features that minimize barriers in order to facilitate disclosures that can not only inspire social support exchange, but also possibly erode the intersectional stigma that prevents disclosure in the first place.

\section{ACKNOWLEDGMENTS}

We are deeply grateful to participants for trusting in us and sharing their experiences. We thank the ACs and reviewers. We also thank Kristen Barta, Oliver Haimson, Olivia Richards, and Carol F. Scott for feedback on earlier drafts of this work. We are also grateful to those who assisted in our recruitment efforts and to Kylie Wojciechowski for conducting some of the interviews. The study was funded by The University of Michigan MCUBED program awarded in 2019 to PI Andalibi and Co-PIs Lacombe-Duncan and Roosevelt.

\section{REFERENCES}

[1] Nazanin Andalibi. 2019. What happens after disclosing stigmatized experiences on identified social media: Individual, dyadic, and social/network outcomes. In Proceedings of the 2019 CHI Conference on Human Factors in Computing Systems (CHI '19), Association for Computing Machinery, Glasgow, Scotland Uk, 1-15. DOI: https://doi.org/10.1145/3290605.3300367

[2] Nazanin Andalibi. 2020. Disclosure, privacy, and stigma on social media: Examining non-disclosure of distressing experiences. ACM Trans. Comput.-Hum. Interact. 27, 3 (May 2020), 18:1-18:43. DOI: https://doi.org/10.1145/3386600

[3] Nazanin Andalibi and Justin Buss. 2020. The Human in Emotion Recognition on Social Media: Attitudes, Outcomes, Risks. In Proceedings of the $2020 \mathrm{CHI}$ Conference on Human Factors in Computing Systems (CHI '20), Association for Computing Machinery, New York, NY, USA, 1-16. DOI: https://doi.org/10.1145/ 3313831.3376680

[4] Nazanin Andalibi and Andrea Forte. 2018. Announcing pregnancy loss on Facebook: A decision-making framework for stigmatized disclosures on identified social network sites. In Proceedings of the 2018 CHI Conference on Human Factors in Computing Systems - CHI '18, ACM Press, Montreal QC, Canada, 1-14. DOI: https://doi.org/10.1145/3173574.3173732

[5] Nazanin Andalibi and Andrea Forte. 2018. Responding to Sensitive Disclosures on Social Media: A Decision-Making Framework. ACM Trans. Comput.-Hum. Interact. 25, 6 (December 2018), 31:1-31:29. DOI: https://doi.org/10.1145/3241044

[6] Nazanin Andalibi, Oliver L. Haimson, Munmun De Choudhury, and Andrea Forte. 2018. Social support, reciprocity, and anonymity in responses to sexual abuse disclosures on social media. ACM Trans. Comput.-Hum. Interact. 25, 5 (October 2018), 28:1-28:35. DOI: https://doi.org/10.1145/3234942

[7] Nazanin Andalibi, Oliver L. Haimson, Munmun De Choudhury, and Andrea Forte. 2016. Understanding social media disclosures of sexual abuse through the lenses of support seeking and anonymity. In Proceedings of the 2016 CHI Conference on Human Factors in Computing Systems (CHI '16), Association for Computing Machinery, San Jose, California, USA, 3906-3918. DOI: https: //doi.org/10.1145/2858036.2858096

[8] Nazanin Andalibi, Margaret E. Morris, and Andrea Forte. 2018. Testing waters, sending clues: Indirect disclosures of socially stigmatized experiences on social media. Proc. ACM Hum.-Comput. Interact. 2, CSCW (November 2018), 19:1-19:23. DOI: https://doi.org/10.1145/3274288

[9] Nazanin Andalibi, Pinar Ozturk, and Andrea Forte. 2017. Sensitive selfdisclosures, responses, and social support on Instagram: The case of \#depression. In Proceedings of the 2017 ACM Conference on Computer Supported Cooperative Work and Social Computing (CSCW '17), Association for Computing Machinery, Portland, Oregon, USA, 1485-1500. DOI: https://doi.org/10.1145/2998181. 2998243

[10] Jonah Bardos, Daniel Hercz, Jenna Friedenthal, Stacey A. Missmer, and Zev Williams. 2015. A national survey on public perceptions of miscarriage. Obstetrics \& Gynecology 125, 6 (June 2015), 1313-1320. DOI: https://doi.org/10.1097/AOG. 0000000000000859

[11] Kristen Barta. 2019. Reclaiming publicness in the face of sexual assault: Social media, disclosure, and visibility. Thesis. Retrieved December 29, 2020 from https://digital.lib.washington.edu:443/researchworks/handle/1773/45159

[12] Natalya N. Bazarova. 2012. Public intimacy: Disclosure interpretation and social judgments on Facebook. 7 Commun 62, 5 (October 2012), 815-832. DOI: https: //doi.org/10.1111/j.1460-2466.2012.01664.x

[13] Rena Bivens. 2017. The gender binary will not be deprogrammed: Ten years of coding gender on Facebook. New Media \& Society 19, 6 (June 2017), 880-898. 
DOI: https://doi.org/10.1177/1461444815621527

[14] Beth Perry Black and Wendy Smith Fields. 2014. Contexts of reproductive loss in lesbian couples. MCN, The American fournal of Maternal/Child Nursing 39, 3 (2014), 157-162. DOI: https://doi.org/10.1097/NMC.0000000000000032

[15] Lindsay Blackwell, Jean Hardy, Tawfiq Ammari, Tiffany Veinot, Cliff Lampe, and Sarita Schoenebeck. 2016. LGBT parents and social media: Advocacy, privacy, and disclosure during shifting social movements. In Proceedings of the $2016 \mathrm{CHI}$ Conference on Human Factors in Computing Systems - CHI '16, ACM Press, Santa Clara, California, USA, 610-622. DOI: https://doi.org/10.1145/2858036.2858342

[16] Amy Brainer, Mignon R. Moore, and Pallavi Banerjee. 2020. Race and ethnicity in the lives of LGBTQ Parents and their children: Perspectives from and beyond North America. In LGBTQ-Parent Families: Innovations in Research and Implications for Practice, Abbie E. Goldberg and Katherine R. Allen (eds.). Springer International Publishing, Cham, 85-103. DOI: https://doi.org/10.1007/978-3-03035610-1_5

[17] Gillian Brockell. Perspective | Dear tech companies, I don't want to see preg nancy ads after my child was stillborn. Washington Post. Retrieved January 5, 2021 from https://www.washingtonpost.com/lifestyle/2018/12/12/dear-techcompanies-i-dont-want-see-pregnancy-ads-after-my-child-was-stillborn/

[18] Hannah Brooks, Carrie D Llewellyn, Tom Nadarzynski, Fernando Castilho Pelloso, Felipe De Souza Guilherme, Alex Pollard, and Christina J Jones. 2018 Sexual orientation disclosure in health care: a systematic review. Br 7 Gen Pract 68, 668 (March 2018), e187-e196. DOI: https://doi.org/10.3399/bjgp18X694841

[19] Grace Burleson, Mustafa Naseem, and Kentaro Toyama. 2020. An exploration of African-American pregnant women's information-seeking behavior in Detroit In Proceedings of the 2020 International Conference on Information and Communication Technologies and Development (ICTD2020), Association for Computing Machinery, Guayaquil, Ecuador, 1-12. DOI: https://doi.org/10.1145/3392561.3394647

[20] Sylvia Burrow, Lisa Goldberg, Jennifer Searle, and Megan Aston. 2018. Vulnerability, harm, and compromised ethics revealed by the experiences of queer birthing women in rural healthcare. Bioethical Inquiry 15, 4 (December 2018), 511-524. DOI: https://doi.org/10.1007/s11673-018-9882-5

[21] Albert C. Cain, Mary E. Erickson, Irene Fast, and Rebecca A. Vaughan. 1964 Children's disturbed reactions to their mother's miscarriages. Psychosomatic Medicine 26, 1 (1964), 58-66. DOI: https://doi.org/10.1097/00006842-19640100000008

[22] Matthew Carrasco and Andruid Kerne. 2018. Queer visibility: Supporting LGBT+ selective visibility on social media. In Proceedings of the 2018 CHI Conference on Human Factors in Computing Systems (CHI '18), Association for Computing Machinery, Montreal QC, Canada, 1-12. DOI: https://doi.org/10.1145/3173574. 3173824

[23] Andre Cavalcante. 2019. Tumbling into queer utopias and vortexes: Experiences of LGBTQ social media users on Tumblr. Journal of Homosexuality 66, 12 (October 2019), 1715-1735. DOI: https://doi.org/10.1080/00918369.2018.1511131

[24] Rosie Charter, Jane M. Ussher, Janette Perz, and Kerry Robinson. 2018. The transgender parent: Experiences and constructions of pregnancy and parent hood for transgender men in Australia. International fournal of Transgenderism 19, 1 (January 2018), 64-77. DOI: https://doi.org/10.1080/15532739.2017.1399496

[25] Stephenie R. Chaudoir and Jeffrey D. Fisher. 2010. The disclosure processes model: Understanding disclosure decision making and postdisclosure outcomes among people living with a concealable stigmatized identity. Psychological Bulletin 136, 2 (2010), 236-256. DOI: https://doi.org/10.1037/a0018193

[26] Alexander Cho. 2018. Default publicness: Queer youth of color, social media and being outed by the machine. New Media \& Society 20, 9 (September 2018), 3183-3200. DOI: https://doi.org/10.1177/1461444817744784

[27] Sheldon Cohen and Harry M. Hoberman. 1983. Positive events and social sup ports as buffers of life change stress. Fournal of Applied Social Psychology 13, 2 (1983), 99-125. DOI: https://doi.org/10.1111/j.1559-1816.1983.tb02325.x

[28] Patricia Hill Collins and Sirma Bilge. 2020. Intersectionality. John Wiley \& Sons.

[29] Lisa Cosgrove. 2004. The aftermath of pregnancy loss: A feminist critique of the literature and implications for treatment. Women \& Therapy 27, 3-4 (March 2004), 107-122. DOI: https://doi.org/10.1300/J015v27n03_08

[30] Nick Couldry and Ulises A. Mejias. 2019. The Costs of Connection: How Data Is Colonizing Human Life and Appropriating It for Capitalism. Stanford University Press.

[31] Shelley L. Craig and Lauren McInroy. 2014. You can form a part of yourself online: The influence of new media on identity development and coming out for LGBTQ youth. Journal of Gay \& Lesbian Mental Health 18, 1 (January 2014), 95-109. DOI: https://doi.org/10.1080/19359705.2013.777007

[32] Christa Craven and Elizabeth Peel. 2017. Queering reproductive loss: Exploring grief and memorialization. Loughborough University. Retrieved July 1, 2020 from https://repository.lboro.ac.uk/articles/chapter/Queering_reproductive_ loss_Exploring grief_and memorialization/9478259

[33] Christina Craven and Elizabeth Peel. 2014. Stories of grief and hope: Queer experiences of reproductive loss. In Queering Maternity and Motherhood: Narrative and theoretical perspectives on queer conception, birth, and parenting.

[34] Kimberle Crenshaw. 1989. Demarginalizing the intersection of race and sex: A Black feminist critique of antidiscrimination doctrine, feminist theory and antiracist politics. University of Chicago Legal Forum (1989). Retrieved from https://chicagounbound.uchicago.edu/uclf/vol1989/iss1/8

[35] Carolyn E. Cutrona and Julie A. Suhr. 1992. Controllability of stressful events and satisfaction with spouse support behaviors. Communication Research 19, 2 (April 1992), 154-174. DOI: https://doi.org/10.1177/009365092019002002

[36] Zoe Darwin and Mari Greenfield. 2019. Mothers and others: The invisibility of LGBTQ people in reproductive and infant psychology. Fournal of Reproductive and Infant Psychology 37, 4 (August 2019), 341-343. DOI: https://doi.org/10.1080/ 02646838.2019.1649919

[37] Joseph Nicholas DeFilippis. 2016. "What about the rest of us?" An overview of LGBT poverty issues and a call to action. Fournal of Progressive Human Services 27, 3 (September 2016), 143-174. DOI: https://doi.org/10.1080/10428232.2016. 1198673

[38] Stefanie Duguay. 2016. "He has a way gayer Facebook than I do": Investigating sexual identity disclosure and context collapse on a social networking site. New Media \& Society 18, 6 (June 2016), 891-907. DOI: https://doi.org/10.1177/ 1461444814549930

[39] Michele J. Eliason and Robert Schope. 2001. Does “don't ask don't tell” apply to health care? Lesbian, gay, and bisexual people's disclosure to health care providers. Journal of the Gay and Lesbian Medical Association 5, 4 (December 2001), 125-134. DOI: https://doi.org/10.1023/A:1014257910462

[40] Simon Adriane Ellis, Danuta M. Wojnar, and Maria Pettinato. 2015. Conception, pregnancy, and birth experiences of male and gender variant gestational parents: It's how we could have a family. Fournal of Midwifery \& Women's Health 60, 1 (January 2015), 62-69. DOI: https://doi.org/10.1111/jmwh.12213

[41] Jennifer Leanne Fairchild. 2009. What might have been: The communication of social support and women's post-miscarriage narrative reconstruction. Ph.D. University of Kentucky, United States - Kentucky. Retrieved September 16, 2020 from http://search.proquest.com/docview/858610979/abstract/ 958D3E1FF2234C61PQ/1

[42] Casey Fiesler, Michaelanne Dye, Jessica L. Feuston, Chaya Hiruncharoenvate, C.J. Hutto, Shannon Morrison, Parisa Khanipour Roshan, Umashanthi Pavalanathan, Amy S. Bruckman, Munmun De Choudhury, and Eric Gilbert. 2017. What (or who) is public? Privacy settings and social media content sharing. In Proceedings of the 2017 ACM Conference on Computer Supported Cooperative Work and Social Computing (CSCW '17), Association for Computing Machinery, Portland, Oregon, USA, 567-580. DOI: https://doi.org/10.1145/2998181.2998223

[43] Berenice Fisher. Affirming social value: Women without children. In Social Organization and Social Processes: Essays in Honor of Anselm Strauss. Transaction Publishers, 420.

[44] Ryan J. Gallagher, Elizabeth Stowell, Andrea G. Parker, and Brooke Foucault Welles. 2019. Reclaiming Stigmatized Narratives: The Networked Disclosure Landscape of \#MeToo. Proc. ACM Hum.-Comput. Interact. 3, CSCW (November 2019), 96:1-96:30. DOI: https://doi.org/10.1145/3359198

[45] Susan B. Goldstein. 2017. Stigma and stigma by association in perceptions of straight allies. Fournal of LGBT Youth 14, 4 (October 2017), 345-358. DOI: https://doi.org/10.1080/19361653.2017.1326867

[46] Kathryn Greene, Valerian Derlega, and Alicia Mathews. 2006. Self-disclosure in personal relationships. In The Cambridge Handbook of Personal Relationships. Cambridge University Press.

[47] Oliver Haimson. 2018. Social media as social transition machinery. Proc. ACM Hum.-Comput. Interact. 2, CSCW (November 2018), 1-21. DOI: https://doi.org/ $10.1145 / 3274332$

[48] Oliver L Haimson, Nazanin Andalibi, Munmun De Choudhury, and Gillian R Hayes. 2018. Relationship breakup disclosures and media ideologies on Facebook. New Media \& Society 20, 5 (May 2018), 1931-1952. DOI: https://doi.org/10.1177/ 1461444817711402

[49] Oliver L. Haimson, Jed R. Brubaker, Lynn Dombrowski, and Gillian R. Hayes. 2015. Disclosure, stress, and support during gender transition on Facebook. In Proceedings of the 18th ACM Conference on Computer Supported Cooperative Work \& Social Computing - CSCW'15, ACM Press, Vancouver, BC, Canada, 1176-1190. DOI: https://doi.org/10.1145/2675133.2675152

[50] Oliver L. Haimson, Jed R. Brubaker, Lynn Dombrowski, and Gillian R. Hayes. 2016. Digital footprints and changing networks during online identity transitions. In Proceedings of the 2016 CHI Conference on Human Factors in Computing Systems (CHI '16), Association for Computing Machinery, San Jose, California, USA, 2895-2907. DOI: https://doi.org/10.1145/2858036.2858136

[51] Oliver L. Haimson, Avery Dame-Griff, Elias Capello, and Zahari Richter. 2019. Tumblr was a trans technology: the meaning, importance, history, and future of trans technologies. Feminist Media Studies (October 2019), 1-17. DOI: https: //doi.org/10.1080/14680777.2019.1678505

[52] G. Hanscombe. 1983. The right to lesbian parenthood. fournal of Medical Ethics 9, 3 (September 1983), 133-135. DOI: https://doi.org/10.1136/jme.9.3.133

[53] Lynne Hillier and Lyn Harrison. 2007. Building realities less limited than their own: Young people practising same-sex attraction on the internet. Sexualities 10, 1 (February 2007), 82-100. DOI: https://doi.org/10.1177/1363460707072956

[54] Aaron Holmes. Facebook is launching a new "coronavirus information center" that will appear at the top of people's News Feeds. Business Insider. Retrieved 
July 1, 2020 from https:/www.businessinsider.com/facebook-coronavirusinformation-center-news-feed-feature-covid-2020-3

[55] Janet Jaffe. 2014. The reproductive story: Dealing with miscarriage, stillbirth, or other perinatal demise. In Women's Reproductive Mental Health Across the Lifespan, Diana Lynn Barnes (ed.). Springer International Publishing, Cham, 159-176. DOI: https://doi.org/10.1007/978-3-319-05116-1_9

[56] Sidney Jourard. 1971. Self-disclosure: An experimental analysis of the transparent self. Wiley, London.

[57] Elaine Kasket. 2009. Protocol for Responding to Participant Distress, Adapted Version for Telephone/Skype.

[58] Karen Kavanaugh and Patricia Hershberger. 2005. Perinatal loss in low-income African American parents. Fournal of Obstetric, Gynecologic, \& Neonatal Nursing 34, 5 (2005), 595-605. DOI: https://doi.org/10.1177/0884217505280000

[59] Janet W. Kenney and Donna T. Tash. 1992. Lesbian childbearing couples' dilemmas and decisions. Health Care for Women International 13, 2 (January 1992), 209-219. DOI: https://doi.org/10.1080/07399339209515993

[60] Sofia Klittmark, Matias Garzón, Ewa Andersson, and Michael B. Wells. 2019 LGBTQ competence wanted: LGBTQ parents' experiences of reproductive health care in Sweden. Scand 7 Caring Sci 33, 2 (June 2019), 417-426. DOI: https: //doi.org/10.1111/scs.12639

[61] Linda L. Layne. 2000. 'He was a real baby with baby things': A material cul ture analysis of personhood, parenthood and pregnancy loss. Fournal of $\mathrm{Ma}$ terial Culture 5, 3 (November 2000), 321-345. DOI: https://doi.org/10.1177/ 135918350000500304

[62] Linda L. Layne. 2014. Motherhood lost: A feminist account of pregnancy loss in America. Routledge.

[63] C. Lee, P. Slade, and V. Lygo. 1996. The influence of psychological debriefing on emotional adaptation in women following early miscarriage: A preliminary study. British fournal of Medical Psychology 69, 1 (1996), 47-58. DOI: https: //doi.org/10.1111/j.2044-8341.1996.tb01849.x

[64] Alexis D. Light, Juno Obedin-Maliver, Jae M. Sevelius, and Jennifer L. Kerns 2014. Transgender men who experienced pregnancy after female-to-male gender transitioning. Obstetrics \& Gynecology 124, 6 (December 2014), 1120-1127. DOI https://doi.org/10.1097/AOG.0000000000000540

[65] Emily R. M. Lind and Angie Deveau (Eds.). 2017. Interrogating pregnancy loss: Feminist writings on abortion, miscarriage, and stillbirth. Demeter Press. DOI https://doi.org/10.2307/j.ctt1wf4cfb

[66] Bruce G. Link and Jo C. Phelan. 2001. Conceptualizing stigma. Annual Review of Sociology 27, 1 (2001), 363-385. DOI: https://doi.org/10.1146/annurev.soc.27.1.363

[67] Carmen H Logie, LLana James, Wangari Tharao, and Mona R Loutfy. 2012 "We don't exist": a qualitative study of marginalization experienced by HIV positive lesbian, bisexual, queer and transgender women in Toronto, Canada. Fournal of the International AIDS Society 15, 2 (September 2012). DOI: https: //doi.org/10.7448/IAS.15.2.17392

[68] Kaitlin Mahar, Amy X. Zhang, and David Karger. 2018. Squadbox: A tool to combat email harassment using friendsourced moderation. In Proceedings of the 2018 CHI Conference on Human Factors in Computing Systems (CHI '18), Association for Computing Machinery, Montreal QC, Canada, 1-13. DOI: https: //doi.org/10.1145/3173574.3174160

[69] Alice E. Marwick and danah boyd. 2011. I tweet honestly, I tweet passionately: Twitter users, context collapse, and the imagined audience. New Media \& Society 13, 1 (February 2011), 114-133. DOI: https://doi.org/10.1177/1461444810365313

[70] M. Chad McBride. 2016. Communicating pregnancy loss: Narrative as a method for change. Women \& Language 39, 1 (Fall 2016), 133-134.

[71] Leslie McCall. 2005. The complexity of intersectionality. Signs 30, 3 (2005), 1771-1800. DOI: https://doi.org/10.1086/426800

[72] Elizabeth A. McConnell, Antonia Clifford, Aaron K. Korpak, Gregory Phillips, and Michelle Birkett. 2017. Identity, victimization, and support: Facebook experiences and mental health among LGBTQ youth. Computers in Human Behavior 76, (November 2017), 237-244. DOI: https://doi.org/10.1016/j.chb.2017.07.026

[73] Elizabeth McConnell, Bálint Néray, Bernie Hogan, Aaron Korpak, Antonia Clifford, and Michelle Birkett. 2018. "Everybody Puts Their Whole Life on Facebook": Identity Management and the Online Social Networks of LGBTQ Youth. International fournal of Environmental Research and Public Health 15, 6 (June 2018), 1078. DOI: https://doi.org/10.3390/ijerph15061078

[74] Ryan A. Miller. 2017. "My voice is definitely strongest in online communities": Students using social media for queer and disability identity-making. fournal of College Student Development 58, 4 (2017), 509-525. DOI: https://doi.org/10.1353/ csd.2017.0040

[75] Michael D. Mink, Lisa L. Lindley, and Ali A. Weinstein. 2014. Stress, stigma, and sexual minority status: The intersectional ecology model of LGBTQ health fournal of Gay \& Lesbian Social Services 26, 4 (October 2014), 502-521. DOI https://doi.org/10.1080/10538720.2014.953660

[76] Aileen Mulvihill and Trish Walsh. 2014. Pregnancy loss in rural Ireland: An experience of disenfranchised grief. Br 7 Soc Work 44, 8 (December 2014), 2290 2306. DOI: https://doi.org/10.1093/bjsw/bct078

[77] R Neugebauer, J Kline, P O'Connor, P Shrout, J Johnson, A Skodol, J Wicks, and M Susser. 1992. Determinants of depressive symptoms in the early weeks after miscarriage. Am 7 Public Health 82, 10 (October 1992), 1332-1339. DOI: https://doi.org/10.2105/AJPH.82.10.1332

[78] Z. Nicolazzo. 2016. "Just Go In Looking Good": The Resilience, Resistance, and Kinship-Building of Trans* College Students. Fournal of College Student Development 57, 5 (July 2016), 538-556. DOI: https://doi.org/10.1353/csd.2016. 0057

[79] Richard Nieva. Facebook tests "things in common" label to try to connect non-friends. CNET. Retrieved July 1, 2020 from https://www.cnet.com/news/ facebook-tests-things-in-common-label-to-try-to-connect-non-friends/

[80] Laura Nyblade, Melissa Stockton, Daniel Nyato, and Joyce Wamoyi. 2017. Perceived, anticipated and experienced stigma: Exploring manifestations and implications for young people's sexual and reproductive health and access to care in North-Western Tanzania. Culture, Health \& Sexuality 19, 10 (October 2017), 1092-1107. DOI: https://doi.org/10.1080/13691058.2017.1293844

[81] Julia Omarzu. 2000. A disclosure decision model: Determining how and when individuals will self-disclose. Pers Soc Psychol Rev 4, 2 (May 2000), 174-185. DOI: https://doi.org/10.1207/S15327957PSPR0402_05

[82] E. Peel. 2010. Pregnancy loss in lesbian and bisexual women: An online survey of experiences. Human Reproduction 25, 3 (March 2010), 721-727. DOI: https: //doi.org/10.1093/humrep/dep441

[83] Elizabeth Peel. 2012. Moving beyond heterosexism? The good, the bad, and the indifferent in accounts of others' reactions to important life events. Psychology of Sexualities Review 3, 1 (2012), 34-46.

[84] Elizabeth Peel and Ruth Cain. 2012. "Silent" miscarriage and deafening heteronormativity: A British experiential and critical feminist account. In Understanding Reproductive Loss: Perspectives on Life, Death and Fertility. 79-92.

[85] Robert Pralat. 2018. More natural does not equal more normal: Lesbian, gay, and bisexual people's views about different pathways to parenthood. fournal of Family Issues 39, 18 (December 2018), 4179-4203. DOI: https://doi.org/10.1177/ 0192513X18810951

[86] Robert Pralat. 2020. Sexual identities and reproductive orientations: Coming out as wanting (or not wanting) to have children. Sexualities (June 2020), 1363460720926967. DOI: https://doi.org/10.1177/1363460720926967

[87] John E. Puddifoot and Martin P. Johnson. 1997. The legitimacy of grieving: The partner's experience at miscarriage. Social Science \& Medicine 45, 6 (September 1997), 837-845. DOI: https://doi.org/10.1016/S0277-9536(96)00424-8

[88] Belle Rose Ragins. 2008. Disclosure disconnects: Antecedents and consequences of disclosing invisible stigmas across life domains. AMR 33, 1 (January 2008), 194-215. DOI: https://doi.org/10.5465/amr.2008.27752724

[89] Leonard Reinecke and Sabine Trepte. 2014. Authenticity and well-being on social network sites: A two-wave longitudinal study on the effects of online authenticity and the positivity bias in SNS communication. Computers in Human Behavior 30, (January 2014), 95-102. DOI: https://doi.org/10.1016/j.chb.2013.07. 030

[90] Christabel L. Rogalin and Jane E. Brooks. 2018. Lesbians achieving pregnancy: The intersections of social location and the heteronormative medicalization of infertility. Sociology Compass 12, 11 (November 2018), e12637. DOI: https: //doi.org/10.1111/soc4.12637

[91] Lauren M. Rossen, Katherine A. Ahrens, and Amy M. Branum. 2018. Trends in risk of pregnancy loss among US women, 1990-2011. Paediatr Perinat Epidemiol 32, 1 (January 2018), 19-29. DOI: https://doi.org/10.1111/ppe.12417

[92] Jennifer D. Rubin and Sara I. McClelland. 2015. 'Even though it's a small checkbox, it's a big deal': stresses and strains of managing sexual identity(s) on Facebook. Culture, Health \& Sexuality 17, 4 (April 2015), 512-526. DOI: https://doi.org/10.1080/13691058.2014.994229

[93] Graham Scambler. 2009. Health-related stigma. Sociology of Health \& Illness 31, 3 (2009), 441-455. DOI: https://doi.org/10.1111/j.1467-9566.2009.01161.x

[94] Anselm Strauss and Juliet Corbin. 1998. Basics of qualitative research: Techniques and procedures for developing grounded theory. SAGE Publications.

[95] Janet M. Turan, Melissa A. Elafros, Carmen H. Logie, Swagata Banik, Bulent Turan, Kaylee B. Crockett, Bernice Pescosolido, and Sarah M. Murray. 2019. Challenges and opportunities in examining and addressing intersectional stigma and health. BMC Med 17, 1 (December 2019), 7. DOI: https://doi.org/10.1186/ s12916-018-1246-9

[96] Michelle Walks. 2007. Breaking the silence: Infertility, motherhood, and queer culture. Fournal of the Motherhood Initiative for Research and Community Involvement 9, 2 (2007).

[97] Mark Warner, Andreas Gutmann, M. Angela Sasse, and Ann Blandford. 2018. Privacy unraveling around explicit HIV status disclosure fields in the online geosocial hookup app Grindr. Proc. ACM Hum.-Comput. Interact. 2, CSCW (November 2018), 181:1-181:22. DOI: https://doi.org/10.1145/3274450

[98] Jaclyn M. White Hughto, Sari L. Reisner, and John E. Pachankis. 2015. Transgender stigma and health: A critical review of stigma determinants, mechanisms, and interventions. Social Science \& Medicine 147, (December 2015), 222-231. DOI: https://doi.org/10.1016/j.socscimed.2015.11.010

[99] Katrien Wierckx, Eva Van Caenegem, Guido Pennings, Els Elaut, David Dedecker, Fleur Van de Peer, Steven Weyers, Petra De Sutter, and Guy T'Sjoen. 2012. Reproductive wish in transsexual men. Hum Reprod 27, 2 (February 2012), 
483-487. DOI: https://doi.org/10.1093/humrep/der406

[100] Erin Wingo, Natalie Ingraham, and Sarah C.M. Roberts. 2018. Reproductive health care priorities and barriers to effective care for LGBTQ people assigned female at birth: A qualitative study. Women's Health Issues 28, 4 (July 2018), 350-357. DOI: https://doi.org/10.1016/j.whi.2018.03.002

[101] Danuta Wojnar. 2007. Miscarriage experiences of lesbian couples. fournal of Midwifery \& Women's Health 52, 5 (September 2007), 479-485. DOI: https://doi. org/10.1016/j.jmwh.2007.03.015

[102] Danuta M. Wojnar and Amy Katzenmeyer. 2014. Experiences of preconception, pregnancy, and new motherhood for lesbian nonbiological mothers. fourna of Obstetric, Gynecologic \& Neonatal Nursing 43, 1 (January 2014), 50-60. DOI: https://doi.org/10.1111/1552-6909.12270

[103] Danuta Wojnar and Kristen M. Swanson. 2006. Why shouldn't lesbian women who miscarry receive special consideration?: A viewpoint. fournal of GLBT Family Studies 2, 1 (January 2006), 1-12. DOI: https://doi.org/10.1300/J461v02n01_01
[104] Marc Ziegele and Leonard Reinecke. 2017. No place for negative emotions? The effects of message valence, communication channel, and social distance on users' willingness to respond to SNS status updates. Computers in Human Behavior 75, (October 2017), 704-713. DOI: https://doi.org/10.1016/j.chb.2017.06.016

[105] Shoshana Zuboff. 2019. The age of surveillance capitalism: the fight for a human future at the new frontier of power (First edition ed.). PublicAffairs, New York.

[106] Supporting Well-being with Guides on Instagram / Instagram Blog. Retrieved July 1, 2020 from https://about.instagram.com/blog/announcements/supportingwell-being-with-instagram-guides

[107] Facebook News Feed Algorithm History | 2019 Update | Wallaroo Media. Retrieved July 1, 2020 from https://wallaroomedia.com/facebook-newsfeedalgorithm-history/ 